\title{
Living with the extreme demand
}

\author{
Teppo Eskelinen
}

Department of social sciences, University of Eastern Finland, teppo.eskelinen@uef.fi

Most of the ethical literature on extreme poverty suggests, that some, if not most, of the incomes of the residents of rich countries ought to be donated to the global poor. Yet complying with this ethical demand becomes increasingly more difficult as the changes in lifestyle in the (post)industrial north demand ever more consumption in order to obtain the necessities for survival in such societies. In this article, I will discuss Peter Singer's famous arguments for the ethical duty to donate one's possessions, and elaborate the conception of needs prevalent in both Singer's theory and the theories of many of his critics. My argument is that we have to recognise a category of needs called 'social necessities' that are neither luxuries nor basic needs. This leads to two main conclusions: first, the space for ethical deliberation on whether to donate to life-saving purposes is socially conditioned; and second, ethical strategies of redistribution ought to be accompanied with institutional changes, which also concern the conditions in wealthy countries.

Key words: ethics, money, needs, poverty, charity, necessities, Peter Singer

\section{Introduction}

In this article I analyse the ethical problem of the duty to donate money for purposes of reduction of extreme poverty. Most of the theory on extreme poverty in applied ethics comes in the form of asking to what extent should an individual be prepared to donate his/her wealth or income to presumably life-saving purposes in distant countries. An important subsequent question is, to what extent is the issue of global poverty reduction a matter of individual morality only, and to what extent is this ethical problem conditioned by societal factors. While it is often acknowledged that institutional changes (in trade, development and so on) are needed to eradicate extreme poverty, the ethical problem remains: whatever institutional changes would do, individual duty to help does not disappear, at least not completely. My argument goes to a different direction in stressing the role of institutional changes: I will focus on the relevance of institutional factors in the social setting of the (potential) donors, rather than in the social setting of the recipients.

My starting point is Peter Singer's famous theory on individual duty to donate to lifesaving purposes abroad, and some criticisms forwarded against him. I will argue that Singer's basic moral intuition is correct and defendable against his critics if correctly understood and contextualised. Yet it has to be elaborated by the recognition of socially conditioned necessities. Particular (yet amendable) social factors can set heavy limits to the 
applicability of Singer's theory, in a way neither Singer nor his critics have sufficiently acknowledged.

\section{Singer and his critics}

In his essay 'Famine, morality and affluence», published already in 1972 (Singer 1972), Singer outlined his argument, which he has later restated and defended at several occasions (Singer 1993, 2000, 2002, 2004, 2009). ${ }^{1}$ According to Singer's argument, any individual ought, morally, to give money to life-saving purposes, as long as poverty-related suffering persists, up to the point in which donations would threaten his/her capacity to meet his/her own basic needs. This is because a human life is always more valuable, and therefore of more moral importance, than the mere inconvenience caused by the incapacity to obtain luxuries. Singer's most famous metaphor illustrating the moral case is the 'child in the pond». Quite like a passer-by can be morally expected to rescue a child about to drown in a shallow pond, even though this would result in getting one's clothes muddy, a wealthy individual ought to donate to charities to save lives of children in poor counties, even though this results in inconveniences related to lower purchasing power (Singer 1997). Similar kinds of arguments have been elaborated by Peter Unger (1996) and Shelly Kagan (1989).

Singer suggests the term 'absolute affluence' to refer to the lifestyle typical to ordinary middle-class westerners, which he yet regards unethical to maintain while severe and relievable suffering persists. The characteristics of 'absolute affluence' sound disquietingly familiar to most residents of the affluent countries.

\footnotetext{
Those who are absolutely affluent $[\ldots]$ have more income than they need to provide themselves adequately with all the basic necessities of life. After buying food, shelter, basic health services, and education, the absolutely affluent are still able to spend money on luxuries. The absolutely affluent choose their food for the pleasures of the palate, not to stop hunger; they buy new clothes to look good, not to keep warm [...] and after all this, there is still money to spend on stereo systems, videocameras and overseas holidays [...] Our affluence means that we have income we can dispose of without giving up the basic necessities of life, and we can use this income to reduce absolute poverty. (Singer 1993: 231-232)
}

Singer's theory, practically calling for voluntary impoverishment, has been criticised heavily. The logical basis of the argument is difficult to challenge (distance does not matter, life is morally more important than convenience). Anyhow there are two other main lines of counter-arguments. First, Singer's belief that charitable giving would be a solution to extreme poverty is naive and most likely misinformed, as deep political and institutional changes are necessary for attaining this goal (Kuper 2002). Second, Singer has unrealistic ideas about human motives and behaviour: it is simply unrealistic to expect people to give close to everything away. Human beings cannot be expected to take helping others as the primary aim in their life (Cullity 2006). ${ }^{2}$ Making such demands can cause indifference towards ethics in general. 
To start with the first criticism, is it feasible to expect that the problem of extreme poverty will be solved by charity? The answer seems to be no. Charitable giving is quite unlikely to lead to a sustained eradication of poverty, even reduction, especially without changes both within global institutions (Pogge 2002; Patomäki \& Teivainen 2004) and in the institutional setting of the poor countries (Risse 2005; Eskelinen 2011; Landes 1998; Rodrik et al. 2004). It is difficult, if not outright impossible, to find examples of charity having caused sustained abolishment of poverty in a country or area. The practices and the very usefulness of aid in poverty reduction has been questioned by a number of scholars (Hancock 1994; Easterly 2006; Moyo 2009; Esteva \& Prakash 1998; Rahnema \& Bawtree 1997), and the point is likely to apply to charities as well (Dichter 2003). The criticism presented against Singer for being naive in his belief in charity as functioning povertyreduction (Kuper 2002), is further provoked by the fact that Singer does not hesitate to present his argument as 'Singer solution to world poverty' (Singer 2000). This is, with a high level of certainty, a grossly mistaken claim.

Nevertheless, one may ask, is this criticism somewhat off the point. If we look at the ethical core of his argument, Singer is discussing the duty to save lives, especially the duty to save lives of children. This is not synonymous with sustained poverty eradication: duty to relieve suffering may exist even if the suffering will eventually continue. To follow Singer's analogy: if for some reason the child is likely to end up in the pond repeatedly, clearly the action of greatest importance would be to seek reasons behind this pattern and to try to affect them. Yet this does not relieve any passer-by from the ethical duty to save the child in the instance. Thus the criticism seems viable and valid and calls for reassessment of Singer's ideas as 'solution to world poverty», but it does not refute Singer's main ethical argument. Indeed, the theory can (and should) be understood as an argument related to the duty to relieve acute suffering, rather than a theory of the political economy of poverty reduction.

The second criticism points to the question, how much can an individual be expected to donate? Is it sensible to expect individuals to give away close to everything they have or receive? This can be, and has been, debated from the viewpoints of both ethics and motivational psychology (I will get back later to psychology). The ethical problem is straightforward: having a certain sum of money, how much and on what grounds can the individual, morally, keep to him/herself given that donating to life-saving charities is an option? And further, how can Singer's claim on the stringent duty to give everything but what is needed for bare basic needs, be challenged? In the next section, I will discuss this problem in detail. ${ }^{3}$

\section{The extreme demand}

Singer counts all consumption above the fulfilment of basic needs as luxuries and extravagancies. Many critics are willing to deem this theory too demanding. Garrett Cullity calls Singer's approach 'the extreme demand», and seeks to find a more plausible theory. Cullity ends up concluding, that reducing spending on life-enhancing matters cannot be 
morally required (Cullity 2004: 174-177). These life-enhancing matters can involve personal development, such as education or the arts (Cullity 2004: 183-184). Cullity suggests a category of goal-dependent needs in addition to basic needs and luxuries, and wants to include fulfilling these goal-dependent needs in the category of spending, which is morally acceptable despite the option of donating - whereas Singer would accept only basic needs to this category.

Another argument for cushioning Singer's ethical demands has been proposed by John Arthur. Arthur suggests that Singer's moral theory can be interpreted in two ways. According to the first interpretation, the 'absolutely affluent' ought to give up their possessions to life-saving purposes as long as they don't lose anything of comparable moral significance in the process; according to the second, they ought to give up their possessions as long as anything of any moral significance is not lost (Arthur 1996: 40). While Singer seems to support the first interpretation, Arthur comes close to Cullity's position: if there is moral (or life-enhancing) significance in spending, such spending is different from obtaining 'luxuries' and therefore ethically acceptable even given the option of donating to charities.

Yet Cullity, Arthur and other critics of Singer's 'extreme demand' accept Singer's general picture of the absolutely affluent»: while enjoyment of the arts can be morally different from, say, buying jewellery, the typical citizen of a rich country is, according to this underlying image, surrounded by choices on how to spend the vast amounts of money left after meeting his/her basic needs. But is this indeed accurate? Or, to put the question another way, why do so many people in the rich countries feel that they are not soaked in resources, but rather struggling? There are two answers suggesting themselves.

The first answer is that the absolutely affluent are so accustomed to high living standards, that their sense of lack and abundance has become distorted. If we compare our everyday life to the conditions experienced in poor countries, we realize that we surround ourselves with luxuries. Indeed, a lot of literature on consumption and ethics has been written to make this point: consumption is a matter of mimicking what one's immediate social environment does, despite of what might be rational or ethical. So consumption is not really a matter of meeting needs, but a matter of signalling belonging to a group (Lichtenberg 1996). A psychological approach would be, then, that people simply are not motivated to direct their spending in an ethical manner; consumption follows a different logic from reacting to drowning children, and the sense of being rich or poor is formed relative to one's neighbours, not relative to a universal standard. This point, of course, only seeks to explain why ethical demands are not met; it is no argument with any normative force as such.

The second answer is that life in the affluent societies really requires so much money that people have less to give to charities than Singer presumes when talking about the 'absolutely affluent». For example, Jerome Segal has attempted to form a 'new picture of the affluent society' by calculating what he calls the need-required income (NRI) (Segal 1998: 177). Segal argues that people feel economically hard-pressed not only because of being accustomed to a high level of consumption, but also because meeting basic needs is ever more expensive. Indeed, the need-required income in rich countries is currently 
very high. Segal defines housing, transportation, food, health care, clothing, education and economic security as 'core needs' (conceptually close to but not synonymous with basic needs) and points out that in the US, the income needed to meet these core needs has significantly increased during the past decades, with the exception of food (Segal 1998: 182-191). ${ }^{4}$

Segal argues that this notion merits 'a new picture of the affluent society'. 'Affluence', then, might be needed just to access the ever more expensive means to meet one's basic needs. Thus it seems possible that affluence does not only refer to vast sums of money left after seeing that one's basic needs are met, but also having no choice but to spend money on ever more expensive means for meeting one's basic needs.

It needs to be noted, that Singer's argument consists of two parts. First, according to the normative argument, one ought to donate money to the extremely poor when meeting one's own basic needs is not threatened. Second, according to the descriptive argument, the western world lives in absolute affluence, and therefore typical citizens in these countries have vast resources in their disposal after meeting their basic needs. It is my intention to challenge the descriptive argument, while I have no reason to challenge the main normative argument or the underlying utilitarian theory. I will base my argument on the claim, that Singer's typology of needs is excessively simplified. By a better typology, it is also possible to seek possibilities to strengthen the force of the normative argument.

Even though Singer's argument and its utilitarian rationale focus on the ethical choices of individuals, these individuals make their choices conditioned by societal contexts. In the case of this argument, the societal context determines how much people have after necessary spending, necessary spending being a realm of inapplication of Singer's demand.

\section{Basic needs and needs hierarchies}

Thus before ethical demands on giving to charities are formulated, a clearer picture on how much can 'the affluent' really spend after meeting basic needs is needed. Remember that Singer accepts, that we see that basic needs are met, and does not expect money needed for these purposes to be donated away. He merely assumes that there will be lot to donate (this being the descriptive aspect of his argument), if his normative argument is accepted. So what does it take to meet one's basic needs in an affluent society? And what causes the NRI to vary and change? Surely, these sums are not constant. My intention is to approach the question by pointing out categories of needs ignored by Singer and his critics, rather than calculating exact figures of NRI for a given country. The aim is to show, what makes the NRI vary, not to show precisely how high it is in a given context.

It is necessary to emphasise that I am not making a distinction between needs and wants (Gasper 2004: 134-137), which would give the concept of need an even more morally pressing quality; this would mean using the concept of needs as meaning almost exclusively basic needs. Of course, needs are not the only, and perhaps not always even the best concept for discussing human well-being. As well, or in addition, one could base 
the discussion on the concept of capabilities (Sen 1999, 2000). Yet 'needs' is the concept used in the prior discussion on the subject, which would make it difficult to develop Singer's theory within another conceptual framework. Further, it makes sense to categorise needs from the perspective of their moral relevance; similar typologies of capabilities would be less useful as a normative tool.

Meeting one's needs is as an end, whereas material goods are only means to meet this end. This leads to the question, what kinds of needs are served with what kinds of goods? In any modern society, money is the most important medium for obtaining the goods necessary for the fulfilment of needs. Access to goods such as food, clothing or housing, is organised by the means of monetary exchange. This list can be completed with medical care, schooling, etc, provided either through government or individual budgets, depending on the political system.

An important underlying question is, what is the relation between needs and the economy? Does wealth mean automatically better needs fulfilment? There are two main strands of thought on the subject. The traditional idea of economic development is premised on the idea of gradual fulfilment of needs, according to a logic of 'hierarchy of needs. From the times of John Locke onwards, the increase of production and added economic value has been seen as providing such gradual fulfilment of needs; first basic needs and then more complex needs. ${ }^{5}$ The traditional opposition to this idea comes from Marxist theory. Marx himself claimed that all poverty is relative: needs grow as the economy grows, and therefore economic growth does not provide with more means to purchase luxuries after meeting constant, objective and biological basic needs (Marx 1988: 28-29).

According to Marx, socially necessary spending increases at the same pace as economic growth. This can surely be regarded as an overstatement: there is an objective aspect to needs as well. Yet it is important to note that Singer's idea of 'the absolutely affluent' is premised on the traditional idea of economic development. An affluent country, therefore, is seen as having solved the 'basic needs problem', people being thus able to use ever more income after meeting basic needs. Are there, then, good reasons to assume that economic growth leads to needs fulfilment by a logic of objective hierarchy of needs: first basic needs, then complex needs? Quite the contrary: in modern capitalist society, no such logic appears to exist: there is no mechanism to see that basic needs are met first. People might well feel compelled to spend their money on meeting some 'complex needs' before basic needs. People might have good reasons to seek objects directly unrelated to basic needs because their social setting evolves in the direction of making them necessary. Marx might have exaggerated his point, but the point was not completely mistaken.

\section{Analysis of needs}

Let me start the analysis by pointing out a problem related to the category of basic needs. How useful is the distinction between basic needs and extravagancies? The problem is that the means to meeting one's basic needs can be totally inadequate or humiliating, or 
they can be totally extravagant. Thus a significant distinction lies also within the category of basic needs, rather than only between basic needs and luxuries.

Consider two individuals. A has inherited a huge fortune, invested it, and gets a steady income of $\$ 10000$ a month from the investments. A uses this income by living an isolated life in a mansion, eating caviar, liver pâté and such. As A lives in isolation and does little outside the mansion, all A's spending goes to basic needs (shelter, food). B, on the other hand, makes a meagre living by doing hard manual work for most of the day, earns $\$ 500$ a month, which pays the rent of a shack, and potatoes and porridge for food. As B keeps his living costs to minimum, he can afford to enjoy a game of football once a month. In these lives of these two imaginary persons, everything except B's monthly football ticket goes under the category of 'basic needs'. Yet it would seem absurd to argue that B's spending is 'extravagant', while A's is not.

So instead of basic needs/extravagancies dichotomy, a definition of a feasible standard of meeting basic needs is needed. ${ }^{6}$ Singer recognises this when arguing that the 'absolutely affluent choose their food for the pleasures of the palate, not to stop hunger; they buy new clothes to look good, not to keep warm', even though the preceding sentence is based on the contrary idea of constant basic needs: 'After buying food, shelter, basic health services, and education, the absolutely affluent are still able to spend money on luxuries.' So it is not sufficient to say, what kinds of goods are sought to meet 'basic' needs. Rather, what is needed is an idea of what is necessary and what is not.

Let me suggest a more nuanced typology of needs than the one Singer leans on, to distinguish more categories of needs from the perspective of moral relevance. My suggestion is, that needs could be divided in categories of bare basic needs (meeting one's basic needs with means of a feasible standard), goal-dependent needs, ${ }^{7}$ extravagancies, and social necessities. The category of social necessities is a difficult one because it is partly overlapping with other categories, yet it is necessary if Singer's argument is to be seen in proper context.

Giving up the means of meeting one's bare basic needs or goal-dependent needs is a situation that can be called plain giving. In this case, the person could enhance his/her life by spending resources on his/herself, but as someone in an acute life-or-death situation needs the same resources even more, an act of donation can be morally required. For example, a pile of music albums can provide enjoyment, thus enhancing enjoyment of one's everyday life. Yet, in comparison with the pressing needs of the malnourished children in the third world, it might be justified to give up these enjoyments in order to relieve acute suffering elsewhere. This is the subject matter of disagreement between Singer and Cullity.

The moral opposite of the category of plain giving is what could be called extravagancies. The term itself implies that there are no elements involved, which would really enhance one's quality of life. Extravagancies are typically, if not necessarily, 'status goods'. They are desired only in order to communicate certain status in a society, and the matter, which goods become status goods in a certain society, is determined by cultural factors. Status goods are objects that are out of reach of the 'ordinary man'. Had this not been the case, they would cease to be status goods. Even if such goods would bring satisfaction, 
they have a different moral status than goods needed for the satisfaction of goal-dependent needs. If something is an extravagance, the possessor can be morally expected to give up this good if this implies avoidance of suffering for someone else, without similar objections as in a case of giving up the possession of a non-extravagant good. Of course it can be difficult to make the distinction between luxuries and objects needed to meet goaldependent needs, as the very privileged are likely to see luxuries as life-enhancing. Yet these difficulties of categorisation are not unresolvable and present no great problem for the purposes of a typology of needs.

Further, and to get to the most crucial point, Singer's argument lacks any notion of society-specific needs. A needs hierarchy, traditional idea of economic development, or a sharp dichotomy between basic goods and luxuries are all premised on the idea of objectivity of needs. Yet, perhaps in line with what Marx indicated, in societies with a high level of penetration of social life by monetary relations, it is very difficult to adjust one's consumption to objects directly needed for meeting basic needs. Rather, ever more complex goods are needed indirectly for meeting basic needs. Food is needed to meet the basic need of nutrition; transport is needed to get to work to obtain money to buy food.

\section{Social necessities and their creation}

Social necessities can be defined as necessary means of meeting one's basic needs. In modern capitalism, there are more such social necessities that are commercialised and ever more expensive: means of transportation, social interaction, communication, education and such. This leads certain material goods and services and related consumption to become social necessities.

To illustrate this point, let us conceive of a society, in which some technological object is needed to get anything done. Imagine that for obtaining an apartment, buying anything, communicating with friends, working and thus receiving a salary, and so forth, everyone in a given society would need to possess a thing called the Gadget. Thus the Gadget would be of very high priority to anyone in this imaginary society and a social necessity of high importance. The Gadget would be also, of course, something that has directly nothing to do with basic needs. You don't eat the Gadget, you don't drink the Gadget, you don't sleep in the Gadget. You don't even trade the Gadget for these goods. Yet quite obviously anyone in such a society lacking a Gadget would be extremely marginalised and have great difficulties meeting one's basic needs, and it would be fair to say that in order to prevent citizens from falling in desperate poverty it should be seen that everyone possesses a Gadget. Alternatively, a societal solution could be found, in which people could again fully function without the possession of a Gadget. Such an alternative solution would not necessarily mean that the standard of living would fall - just that acquiring goods necessary for meeting needs is organised differently.

It can well be argued that computers with internet access and mobile phones have this role in contemporary society: it is very difficult to function for meeting one's basic needs without them. Similarly, private cars might have a similar status in some cities with no 
decent systems of public transport. And, again analogously to the imaginary society in the example above, full functioning without such goods could be made possible: seeing that goods can be obtained without the Gadget in the example, providing public services in real-world society.

Anything resembling the 'Gadget' of the example will form a difficulty for Singer's conception of needs, and while the example is of course highly imaginary, objects with similar social functions do exist. Such necessities are clearly not objects directly needed for meeting basic needs. Equally clearly they are not (necessarily) life-enhancing nor extravagant for the very reason that from the viewpoint of the individual, they are necessary. Therefore, it is not sufficient to refer to objects needed for the immediate satisfaction of basic needs, but rather, it has to be pointed what objects are necessary for functioning in a society so that basic needs can be met (Goodin 1995: 250). The NRI increases not only with the items needed to meet basic needs becoming more expensive, but by the expansion of the category of social necessities.

Further, this means less space for ethical deliberation when it comes to Singer's demand. When people are demanded to cease consuming necessities on the basis that they are neither basic nor life-enhancing, the argument can be ethically unreasonable, in addition to being psychologically optimistic. Again, 'the Gadget' is neither an object for directly meeting basic needs, nor a luxurious item that an individual could be expected to give away to be able to donate to charities. On the other hand, a reorganisation of the society to liberate people from the need to possess a Gadget would cause consumption needs to decline while maintaining the standard of living constant.

The economic reality in modern Western society does not consist simply from receiving a salary, seeing that one's basic needs are met, and then deciding how to spend the remaining sum. First, merely being able to receive one's salary involves a complex pattern of spending. One needs to live in an area with employment opportunities, which often practically means living in an area with considerably high housing costs or in an area with little alternatives to owning a car (Manhattan residents don't spend highly on rents necessarily because they prefer extravagant housing but because the housing costs are so high; residents of sprawling cities don't drive only because they prefer to avoid the discomfort of waiting for a bus but also because there might be no alternatives to driving). Second, just remaining in the active workforce, and thus receiving a salary, often involves considerable 'spending on oneself' - ongoing education, maintaining right kinds of social relations, networks and images. Third, while reference to technological objects like mobile phones might seem trivial, every society involves some technological solutions, which are necessary to access if one is to live as a part of the society. In the contemporary society, it is very difficult to live without easy access to computers and communication technology.

This all relates to the very functions of capitalist economy, which has a peculiar relation with needs satisfaction, with its constant push for the creation of new markets and new demand. This reality is quite distant from the Lockean progress narrative. As I argued above, in a Marxist fashion, a growing economy tends to create new areas of necessities for functioning in a society. Ivan Illich calls such necessities radical monopolies. The concept refers to a 'monopoly' of a product, instead of the (traditional) notion of mono- 
poly as a monopoly of a brand. If the only soft drink in the market is Pepsi, one can still choose to drink water or beer instead; this is a monopoly. Had soft drinks been the only available means to ease one's thirst, soft drinks would be in the position of a radical monopoly (Illich 1973: 51-57). It is reasonable to assume that establishing such monopolies is an active and deliberate pursuit because radical monopoly is an ideal situation for the producer. For example, for a car manufacturer it is likely to be more profitable to establish a situation in which a car is a social necessity (radical monopoly) than a situation in which the manufacturer has an advantage in competition over another car manufacturer but bicycles and buses are widely used.

According to Illich (1973), the economic system looks for these kinds of radical monopolies in order to maintain growth. For example, when the mobile phone becomes the cultural norm for communication with friends, when it becomes difficult to maintain employment without being reachable by mobile phone, and when the public phone booths disappear from the streets, a radical monopoly has established itself - one genuinely needs a mobile phone. Mobiles phones, even though they have nothing to do with basic needs, become necessities.

Singer's main problem lies here. The gap between what one theoretically ought to donate (if only goods directly needed for meeting basic needs is seen as morally justified spending on oneself), and what one practically can donate given all social necessities, gets ever wider. The problem is structural, not psychological. Economic measures like personal income fail to reflect, what people are (more or less) compelled to buy. Most people can afford a mobile phone, whereas this would have been a distant luxury 50 years ago. Yet this does not make the mobile phone a luxury, since the mobile phone is essential in a modern society, whereas 50 years ago communication was handled differently.

\section{Liberating resources}

To get even further with the analysis, there are different kinds of social necessities in terms of their moral status (moral meaning here life-enhancing as in Cullity). Some social necessities are life-enhancing. It is debatable, whether this applies to technological objects (presumably most people would argue that they are life enhancing, but in a very trivial manner). So let us take another kind of example of social necessities: schooling and literacy. Schooling is clearly a social necessity, and it is practically necessary for everyone in a modern society to be literate. This requires some resources to be spent on education (public or private depending on the political system). Yet schooling is clearly life-enhancing. Schooling and literacy are not like the Gadget in the example above, which is just a technological solution to functions that could be organised differently, making social necessities less complex and potentially less expensive. ${ }^{8}$

On the other end of the moral scale, some social necessities are not merely replaceable, but also harmful in the sense that if people would collectively cease buying and using such goods or services, everyone would be better off. They thus form a classical prisoner's dilemma situation. It would be unreasonable to ask individuals to unilaterally cease using 
such necessities, yet collective action to this direction would improve everyone's situation. Take the private car again as an example. If I have the need to move from place A to place $\mathrm{B}$, a fast and flexible mode of transport is a great asset. Thus the car serves my need perfectly well. Yet, when close to everyone possesses a private car, roads become jammed and cities become planned according to the assumption that people have a car in their possession. Consequently, people have to travel longer periods and distances than if no-one possessed a car; the need for transport is served worse, not better.

Another example of the prisoner's dilemma situation in regard to needs is suggested by Robert E. Goodin: legal aid. It is in everyone's interest that the legal system functions well, and therefore the availability of legal aid seems to be a positive issue. Yet a situation in which one has to get legal aid in order to get a fair trial, since by assumption everyone else is getting legal aid, is for no-one's benefit (the lawyers apart). Had no one got this 'asset', people would be collectively better off (Goodin 1995: 257-258).

As a result, some needs could be served better by using less resources (cars, legal aid) on them, if this can be organised collectively. Thus, paradoxical as it may seem, giving up collectively something, which is clearly beneficial and useful from an individual viewpoint, may lead to a situation in which needs are served even better. These are things that people would genuinely cease to need, if they were able to collectively give them up. In the process, therefore, nothing that is valued or needed would strictly speaking be lost. On the other hand, asking an individual person to give up such a good because it is 'luxurious' is clearly a misunderstanding of the nature of such necessities.

Therefore, it seems that in the task of motivating people to donate the income they can donate, identifying and reducing spending on such necessities, which involve prisoner's dilemma cases, would be of importance. From the perspective of meeting needs, the strategy of more resources can thus be complemented, and sometimes even replaced, with a strategy of providing less. As the starting point for motivation for donating, this is promising. Clearly, an ethical argument for donating resources to the needy has more force, if cases are to be found in which correct planning leads to better needs-fulfilment with less resources. To get back to the example of cars, if the need for transport is served better by transport planning making public transport efficient, people have the genuine choice whether or not to buy a car, selling the car does not mean more difficulties in meeting one's needs, and thereby the realm of application of Singer's ethical demand is extended (a car ceases to be a necessity, and becomes a kind of extravagancy). Consequently, the demand is also highly more reasonable and more likely to achieve resonance.

So where does the argument lead to? First, individuals in rich countries clearly have the moral duty to donate money for life-saving purposes. Here Singer is correct. But this duty only applies as far as individuals have real possibilities to give money away: they can make a genuine choice (again, given that they are not expected to donate the resources they need for meeting basic needs). Individuals really have to have additional income after meeting their basic needs to be expected to donate their money. It is thus necessary to analyse, what is their realm of ethical choice, given that their own basic needs can be seen to be met before this ethical deliberation. It is necessary thus to make a distinction between the extreme demand, arguing that we have stringent duties within the realm of our ethical 
choice, and the impossible demand, expecting individuals to donate away resources that they in fact need for meeting basic needs.

This analysis leads to two further questions. First, how can the amount of money needed to purchase necessities be reduced? There is a need for a societal programme to see that this takes place, if the ethical choice presented by Singer is to be genuinely binding. This, for its part, requires an analysis of social necessities, in the light of a distinction between life-enhancing necessities and others. The second question regards ethical motivation. Is it better to expect altruism, or to seek solutions, in which even less altruistic motivations can bring a better outcome? (After all, outcome is what matters to a utilitarian). Of course, individuals sometimes act in a completely altruistic manner. But if the point is that more resources are needed for life-saving purposes, a purely normative argument might not lead very far. If the ethical demand of donating resources can be accompanied with a societal programme, which leads to the donor's experience of increased rather than decreased capacity to meet one's needs, it is considerably easier to convince people to donate money. If such societal programme can manage to decrease prisoner's dilemma cases, the moral motivation for donations is likely to increase. This requires replacing the idea of 'gradual fulfilment' of needs with the notion of social necessities (which have the tendency to get more complex and expensive, even though this tendency is not deterministic).

\section{Conclusion}

Pointing out the moral duty to donate to life-saving purposes says nothing about the society-specific needs, which are not absolute or objective. While indeed people biologically need food and don't need mobile phones, biologically non-necessary goods can (and do) become necessities in actual social settings. The 'needs hierarchy' idea of gradual needs fulfilment, in which first basic and then complex needs get fulfilled, is clearly mistaken as a description of actual consumption dynamics in capitalist societies. Therefore the dichotomy between basic needs and luxuries is analytically inadequate. This has lead Singer to form an excessively demanding theory on the duty to donate to charities: he sees anything except goods directly required to meet basic needs as luxuries, and thus forms a mistaken descriptive picture of the 'absolutely affluent'. A more realistic picture of affluence is formed if we reconsider the underlying typology of needs by recognising the category of social necessities. This also gives credibility to Singer's (viable) normative argument.

A further conclusion is that the amount of monetary resources needed for necessities can also be politically altered, and this is for general benefit when these necessities are not life-enhancing, especially in prisoner's dilemma cases. Radical monopolies can be tackled, but this is not (and cannot be) an issue of individual morality. Focusing exclusively on individual moral responsibilities leads the theory to a dead-end of either having to accept the constant rise in the cost of necessities, these resources being thus away from even potentially donated money and the scope of ethical deliberation, or requiring people 
to donate away resources they genuinely need for accessing social necessities, which seems implausible.

Singer's critics who argue that he has no 'politics' in his idea of poverty reduction are correct, but they fail to recognise that this lack of 'politics' concerns also the situation of the people living in rich countries, not only politics of poverty reduction in the poor countries. Several cosmopolitan philosophers have recently emphasised, that poverty eradication requires changes in global institutional structures (Pogge 2002; Kuper 2002), and several others have noted that the quality of institutions in poor countries is key to sustained poverty eradication. These theories do not take into account the relevance of structural matters within the donor countries. Yet such matters are of importance, as political/ structural issues determine the extent of social necessities in the society.

Yet Singer's ethical challenge to any individual remains important. The matter is not to forget about poverty-related suffering as an ethical problem for the individual, but to complement the ethical question and give it a plausible context.

\section{Notes}

${ }^{1}$ While discussing an argument presented already in 1972 could be seen as pointless, exactly the fact that Singer has very recently restated the same argument makes the analysis of this argument timely.

${ }^{2}$ Of course, one line of criticism is denouncing poverty reduction altogether as ethically counter-productive, a kind of 'bad samaritan' case (Malthus 1999; Hardin 1996). Yet I choose to grant, that povertyrelated suffering is bad and poverty eradication is ethically good.

${ }^{3}$ For the sake of focus, I am not discussing here practical matters related to donations further. Thus it can be taken for granted, that money can indeed be transferred to life-saving purposes abroad, even as easily as 'taking it around the corner' (Singer 1972). It can also be taken for granted that there is a given sum which can save a child's life (with no need to define it here), and that the choice of the most efficient development agency presents no ethical problem.

${ }^{4}$ One should note, though, that Segal's work dates 15 years back; this should be kept in mind when discussing tendencies of prices.

${ }^{5}$ For an intresting discussion on the idea of needs and economic growth, see Achterhuis (1993). For an illuminating historical example of the idea, that the 'basic needs problem' would be solved at some stage of economic growth, see Keynes (1972 [1931]).

${ }^{6}$ I will refer to basic needs met to such feasible standard as bare basic needs.

${ }^{7}$ Need for non-basic but life-enhancing goods, as in Cullity's theory.

${ }^{8}$ Incidentally, Ivan Illich does think that schooling represents a radical monopoly with all its negative connotations (Illich 1971), yet most people, along with myself, would believe that schooling is lifeenhancing and a crucial right.

\section{References}

Achterhuis, H. (1993) Scarcity and sustainability. In Global ecology. A new arena of political conflict, ed. W. Sachs, pp. 104-116. London: Zed Books.

Arthur, J. (1996) Rights and the duty to bring aid. In World hunger and morality, eds. W. Aiken \& H. LaFollette, pp. 39-50. Upper Saddle River, NJ: Prentice Hall. 
Cullity, G. (2004) The moral demands of affluence. Oxford: Clarendon Press.

Easterly, W. (2006) The white man's burden. Why the west's efforts to aid the rest have done so much ill and so little good. New York: Penguin Press.

Eskelinen, T. (2011) Harming the global poor. On the causal and moral role of institutions. SATS, 12 (1), pp. 89-103.

Esteva, G. \& Prakash, M. S. (1998) Grassroots post-modernism. Remaking the soil of cultures. London: Zed Books.

Gasper, D. (2004) The ethics of development. Edinburgh: Edinburgh University Press.

Goodin, R. E. (1995) Utilitarianism as a public philosophy. Cambridge: Cambridge University Press.

Hancock, G. (1994) Lords of poverty. The power, prestige and corruption in the international aid business. New York: Atlantic Monthly Press.

Hardin, G. (1996) Lifeboat ethics. The case against helping the poor. In World hunger and morality, eds. W. Aiken \& H. LaFollette, pp. 5-15. Upper Saddle River, NJ: Prentice Hall.

Landes, D. (1998) The wealth and poverty of nations: Why some are so rich and some so poor. New York: Norton.

Kagan, S. (1989) The limits of morality. Oxford: Oxford University Press.

Keynes, J. M. (1972 [1931]) Economic possibilities for our grandchildren. In Essays in persuasion. The collected writings of John Meynard Keynes, vol. 9. London: MacMillan.

Kuper, A. (2002) More than charity. Cosmopolitan alternatives to the 'Singer solution'. Ethics and International Affairs, 16 (2), pp. 107-120.

Lichtenberg, J. (1996) Consuming because others consume. Social Theory and Practice, 22 (3), pp. 273-297.

Illich, I. (1971) Deschooling society. London: Calder \& Boyars.

Illich, I. (1973) Tools for conviviality. New York: Harper \& Row.

Malthus, T. (1999) An essay on the principles of population. Oxford: Oxford University Press.

Marx, K. (1988) The economic and philosophic manuscripts of 1844 and the communist manifesto. Translated by Martin Milligan. Buffalo, NY: Prometheus Books.

Moyo, D. (2009) Dead aid. Why aid is not working and how there is another way for Africa. New York: Allen Lane.

Patomäki, H. \& Teivainen, T. (2004) A possible world. Democratic transformation of global institutions. London \& New York: Zed Books.

Pogge, T. (2002) World poverty and human rights. Cosmopolitan responsibilities and reforms. Cambridge: Polity Press.

Rahnema, M. \& Bawtree, V. (1997) The post-development reader. London: Zed Books.

Risse, M. (2005) How does the global order harm the poor? Philosophy and Public Affairs, 33 (4), pp. 349-376.

Rodrik, D., Subramanian, A. \& Trebbi, F. (2004) Institutions rule: The primary of institutions over geography and integration in economic development. Journal of Economic Growth, 9 (2), pp. 131-165.

Segal, J. (1997) Consumer expenditures and the growth of NRI. In Ethics of consumption: The good life, justice, and global stewardship, eds. D. A. Crocker \& T. Linden, pp. 176-197. Lanham, MA: Rowman \& Littlefield.

Sen, A. (1999) Commodities and capabilities. New Delhi: Oxford University Press.

Sen, A. (2000) Development as freedom. New York: Anchor Books.

Singer, P. (1972) Famine, affluence and morality. Philosophy and Public Affairs, 1 (1), pp. 229-243.

Singer, P. (1993) Practical ethics. Cambridge: Cambridge University Press.

Singer, P. (1997) The drowning child and the expanding circle. The New Internationalist, 289 (4), pp. 28-30. 
Singer, P. (2000) Writings on an ethical life. New York: Ecco.

Singer, P. (2002) Poverty, facts, and political philosophies: Response to 'More than charity'. Ethics and International Affairs, 16 (1), pp. 121-124.

Singer, P. (2004) Outsiders. Our obligations to those beyond our borders. In The ethics of assistance. Morality and the distant needy, ed. Deen K. Chatterjee, pp. 11-32. Cambridge: Cambridge University Press.

Singer, P. (2009) The life you can save: Acting now to end world poverty. New York: Random House. Unger, P. (1996) Living high and letting die. New York: Oxford University Press. 